\title{
Etiology of Pituitary Tumors: A Case Control Study
}

\author{
Lige LENG ${ }^{1,2}$, Yazhuo ZHANG ${ }^{1,2}$ \\ ${ }^{1}$ Beijing Neurosurgical Institute, Beijing, China \\ ${ }^{2}$ Capital Medical University, Beijing, China
}

\section{ABSTRACT}

AIM: Pituitary tumors are generally benign, but may be associated with some morbidities. The aim of this study was to identify the risk factors for pituitary tumors.

MATERIAL and METHODS: A population-based case-control study on the potential risk factors of pituitary tumors was conducted in China. The personal interview technique was used to gather information on medical and reproductive history, taste, and cigarette smoking from 204 pituitary tumor cases and 246 controls aged between 6 and 82 years.

RESULTS: The risk of tumor was reduced when the interviewee was a worker. The risk was raised with spicy taste, mobile phone use, duration of use, characteristics, and taking vitamins. No significant association was observed with gender, age, education, marriage, speed of eating, fat intake, other tastes (salt, sour, sweet), medical and reproductive history, female sex hormones, cigarette smoking, tea drinking, wine drinking, menses, and oral contraceptive use, whether the interviewee was a farmer.

CONCLUSION: Increased risk for pituitary tumors is related with spicy taste, mobile phone use, duration of use, characteristics, taking vitamins and possibly a reduced risk is related with the interviewee being a worker. Further investigations are needed to clarify the causes of these associations.

KEYWORDS: Etiology, Pituitary tumor, Risk factor

\section{INTRODUCTION}

Pituitary tumors arise from the pituitary gland and comprise $10 \%$ to $15 \%$ of all diagnosed intracranial tumors $(2,7)$. Most of them are benign and adenomas make up the larger group of pituitary tumors. These tumors are slow growing and usually benign but may invade adjacent structures and cause some neurological deficits.

Pituitary adenomas may be hormone-secreting or non-functioning tumors (15). Despite their predominantly benign nature, they are associated with substantial morbidity, through compression of surrounding structures and oversecretion of pituitary hormones (15). Hormone-secreting adenomas most frequently produce prolactin, leading to hyperprolactinemia, with resulting amenorrhoea, galactorrhea, impotence, and visual disturbances. Acromegaly is secondary to oversecretion of growth hormone and Cushing syndrome from an adrenocorticotropin-secreting pituitary tumor (15). The symptoms of non-functioning tumors develop with compression of the optic chiasm, hypothalamus, and surrounding structures $(2,15,23)$.

The etiology of pituitary tumors is not well known (15). The genetic syndromes Multiple endocrine neoplasia 1 (MEN1) and Carney complex (CNC) are associated with increased risk of pituitary tumor but constitute a small proportion of tumor cases $(3,13,15)$. Germline mutations in the aryl hydrocarbon receptor interacting protein (AIP) gene has recently been shown in some growth hormone-secreting pituitary adenomas $(15,24)$. There are a few studies on the potential risk factors for the development of pituitary tumors and these studies are mostly focused on the use of oral contraceptives $(6,12,14$ $16,21,26)$ or parity $(1,5)$. The reason of these studies is the possible causal role of estrogens in the development of other 
tumors, with some having reported on twinning (9), familial risks (10), or associations with other neoplasms $(11,15)$.

A population-based case control study in China for the determination of potential risk factors for pituitary tumors was conducted. Pituitary tumor cases and controls were included in this study.

\section{MATERIAL and METHODS}

\section{Study Design and Settings}

A case-control study on the etiology of pituitary tumors was performed at the Beijing Tiantan Hospital, China. The cases and the controls were from Beijing, Heilongjiang, Heinan, Hubei province.

A pituitary tumor had been diagnosed in the eligible cases between 1 December 2006 and 28 February 2010. The age of the cases ranged from 6 to 82 years and all were residents of the region where the study was conducted at the time of diagnosis.

A pituitary tumor was defined according to the International Classification of Diseases revision 10 (25) as topography C75.1, D35.2, or D44.3.

The date of diagnosis was defined as the date of the first scan that revealed a space-occupying lesion in the pituitary gland or, if not available, the date of pathological diagnosis (15).
The diagnosis was made by two doctors in the neurosurgical department or pathology department in Beijing Tiantan Hospital. The study was approved by the Ethics Committee of each institution and was based on the criteria of the Helsinki convention. Informed consent was obtained from each patient. The inclusion and exclusion criteria for the patients in this study were: 1) Patients gave informed consent to be included; 2) Patients were excluded if they had a previous diagnosis of an intracranial neoplasia. 3) Cases were excluded because of patient refusal $(n=31)$, or no reply $(n=27)$.

A structured computer-assisted interview using Blaise software (18), with answers being entered directly into the questionnaire program on a laptop computer, was used for interview (15).

\section{Statistical Analysis}

In order to obtain odds ratios (OR) for the risk of a pituitary tumor in relation to the risk factors that were investigated, an unconditional logistic regression model was used (15). All ORs were adjusted for age, education, sex, interview year, and Townsend deprivation score which is a socioeconomic index based on the subject's residential postcode (22). The statistical package Stata was used in all analyses (17). All $p$ values presented are two-sided. $P \leq 0.05$ was defined as significant.

Table I: Characteristics of Study Participants

\begin{tabular}{|c|c|c|c|c|}
\hline \multirow{2}{*}{ Characteristic } & \multicolumn{2}{|c|}{ Cases $(n=204)$} & \multicolumn{2}{|c|}{ Controls ( $n=246$ ) } \\
\hline & $\mathbf{N}$ & $\%$ & $\mathbf{N}$ & $\%$ \\
\hline \multicolumn{5}{|l|}{ Sex } \\
\hline Male & 89 & 43.7 & 136 & 44.8 \\
\hline Female & 115 & 56.3 & 110 & 55.2 \\
\hline \multicolumn{5}{|l|}{ Age at reference date (years) } \\
\hline $6-20$ & 20 & 9.8 & 22 & 8.9 \\
\hline $20-39$ & 42 & 20.6 & 48 & 19.5 \\
\hline $40-59$ & 80 & 39.2 & 106 & 43.1 \\
\hline $60-83$ & 64 & 31.4 & 70 & 24.5 \\
\hline \multicolumn{5}{|l|}{ Marital status } \\
\hline Single & 60 & 29.4 & 72 & 29.3 \\
\hline Married/cohabiting & 110 & 53.9 & 128 & 52.0 \\
\hline Separated/divorced & 24 & 11.8 & 26 & 10.6 \\
\hline Widowed & 6 & 2.9 & 14 & 5.3 \\
\hline Not known & 0 & 0 & 2 & 0.8 \\
\hline \multicolumn{5}{|l|}{ Education } \\
\hline Illiteracy & 2 & 1 & 1 & 0.4 \\
\hline Primary education & 10 & 5 & 6 & 2.4 \\
\hline Junior middle education & 22 & 10.8 & 30 & 12.2 \\
\hline Senior middle education & 122 & 59.8 & 140 & 56.9 \\
\hline College graduate and above & 48 & 23.5 & 69 & 28.0 \\
\hline
\end{tabular}




\section{RESULTS}

In the study period, a total of 450 cases who had appropriate age and residence criteria were included in this study. Characteristics of study participants are presented in Table I. Tumor risk was reduced when the interviewee was a worker $(P=0.01731)$. The risk was raised with spicy taste, mobile phone use, duration of use, characteristics, and taking vitamins $(P=0.01630,<0.00001,<0.00001,0.0500,0.03594$, respectively). In other analyses, the risk was again raised with mobile phone use (OR, 7. 6; 95\% Cl, 2.6-21.4), duration of use (OR, 8.5; 95\% Cl, 2.8-24.4), spicy taste (OR, 2.2; 95\% Cl, 1.6-4.4), characteristics (OR, 1.2; 95\% Cl, 1.0-2.2), and taking vitamins (OR, 1.5; 95\% Cl, 1. 2- 2 .4). No significant association was detected with gender, age, education, marriage, speed of eating, fat intake, other taste (salt, sour sweet), medical and reproductive history, female sex hormones, cigarette smoking, tea drinking, wine drinking, menses, oral contraceptive use, and whether the interviewee was a farmer $(P=0.15757$, $0.94016,0.88658,0.96099,0.37287,0.32429,0.24349$, $0.95711,0.69128,0.06556,0.51930,0.26127,0.66306$, $0.988350 .688390 .5673,0.8953$ respectively). Characteristics were divided into seven levels from cheerful to depression.
Speed of ingestion of food was divided into three levels from slow to fast. Each favorite taste was divided into five levels from dislike to like. Regular cigarette smoking, tea drinking, wine drinking, and whether the interviewee was a farmer were recorded and a detailed analysis was performed (Tables II, III, IV, V).

\section{DISCUSSION}

This is the first study to explore a wide range of potential risk factors for pituitary neoplasms. Positive associations of pituitary adenoma risk with spicy taste, mobile phone using, duration of use, characteristics, taking vitamins $(\mathrm{P}=0.01630$, $<0,00001,<0.00001,0.0500,0.03594$, respectively) were observed. The risk was increased with mobile phone use (OR, 7. 6; 95\% Cl, 2.6-21.4), duration of mobile phone use (OR, 8.5; 95\% Cl, 2.8-24.4), spicy taste (OR, 2.2; 95\% Cl, 1.6-4.4), characteristics (OR, 1.2; 95\% Cl, 1.0-2.2), and taking vitamins (OR, 1.5; 95\% Cl, 1.2-2.4). The tumor risk was significantly raised in mobile phone use.

There are 2 previous studies investigating risk of pituitary tumor in relation to use of mobile phone $(15,20)$. These studies

Table II: Risk of a Pituitary Tumor in Relation to Regular Cigarette Smoking at any Time

\begin{tabular}{|c|c|c|c|c|c|c|}
\hline \multirow{2}{*}{ Factor } & \multicolumn{2}{|c|}{ Cases $(n=204)$} & \multicolumn{2}{|c|}{ Controls $(n=236)$} & \multirow[t]{2}{*}{ OR } & \multirow[t]{2}{*}{$\mathbf{P}$} \\
\hline & $\mathbf{N}$ & $\%$ & $\mathbf{N}$ & $\%$ & & \\
\hline \multicolumn{7}{|c|}{ Regular smoking } \\
\hline No & 120 & 58.8 & 144 & 61.0 & \multirow{11}{*}{$1.1(0.4-1.4)$} & \multirow{11}{*}{0.231} \\
\hline Yes & 84 & 41.2 & 92 & 39.0 & & \\
\hline \multicolumn{5}{|c|}{ Total cumulative years smoked } & & \\
\hline$<10$ & 32 & 15.7 & 42 & 19.8 & & \\
\hline $10-19$ & 45 & 22.1 & 40 & 16.9 & & \\
\hline $20-29$ & 5 & 2.4 & 8 & 3.4 & & \\
\hline z 30 & 2 & 1.0 & 2 & 0.8 & & \\
\hline \multicolumn{5}{|c|}{ Cigarettes /day } & & \\
\hline$<10$ & 42 & 20.6 & 34 & 14.4 & & \\
\hline $10-19$ & 21 & 10.3 & 45 & 19.1 & & \\
\hline z 20 & 21 & 10.3 & 13 & 5.5 & & \\
\hline
\end{tabular}

Table III: Risk of a Pituitary Tumor in Relation to Regular Tea Drinking at any Time

\begin{tabular}{|c|c|c|c|c|c|c|}
\hline \multirow{2}{*}{ Factor } & \multicolumn{2}{|c|}{ Cases $(n=204)$} & \multicolumn{2}{|c|}{ Controls $(n=236)$} & \multirow[t]{2}{*}{ OR } & \multirow[t]{2}{*}{$\mathbf{P}$} \\
\hline & $\mathbf{N}$ & $\%$ & $\mathbf{N}$ & $\%$ & & \\
\hline \multicolumn{7}{|c|}{ Regular tea drinking } \\
\hline No & 164 & 80.4 & 178 & 87.3 & \multirow{7}{*}{$1.2(0.7-1.6)$} & \multirow{7}{*}{0.663} \\
\hline Yes & 40 & 19.6 & 58 & 24.6 & & \\
\hline \multicolumn{5}{|c|}{ Total cumulative years } & & \\
\hline$<10$ & 32 & 15.7 & 42 & 17.8 & & \\
\hline $10-19$ & 6 & 3.0 & 10 & 4.2 & & \\
\hline $20-29$ & 2 & 1.0 & 4 & 1.6 & & \\
\hline z 30 & 0 & 0 & 2 & 0.8 & & \\
\hline
\end{tabular}


Table IV: Risk of a Pituitary Tumor in Relation to Regular Wine Drinking at any Time

\begin{tabular}{|c|c|c|c|c|c|c|}
\hline \multirow{2}{*}{ Factor } & \multicolumn{2}{|c|}{ Cases $(n=204)$} & \multicolumn{2}{|c|}{ Controls (n = 236) } & \multirow[t]{2}{*}{ OR } & \multirow[t]{2}{*}{$\mathbf{P}$} \\
\hline & $\mathbf{N}$ & $\%$ & $\mathbf{N}$ & $\%$ & & \\
\hline \multicolumn{7}{|c|}{ Regular wine drinking } \\
\hline Yes & 94 & 46.1 & 106 & 44.9 & \multirow{7}{*}{$1.1(0.8-1.2)$} & \multirow{7}{*}{0.988} \\
\hline \multicolumn{5}{|c|}{ Total cumulative years } & & \\
\hline $10-19$ & 45 & 22.1 & 32 & 13.6 & & \\
\hline $20-29$ & 6 & 3.0 & 9 & 3.8 & & \\
\hline z30 & 1 & 0.5 & 0 & 0 & & \\
\hline \multicolumn{5}{|c|}{ ml /day } & & \\
\hline$<150$ & 60 & 29.4 & 65 & 27.5 & & \\
\hline
\end{tabular}

Table V: Risk of a Pituitary Tumor in Relation to Ever Regular Using Pesticides

\begin{tabular}{|c|c|c|c|c|c|c|}
\hline \multirow{2}{*}{ Factor } & \multicolumn{2}{|c|}{ Cases $(n=204)$} & \multicolumn{2}{|c|}{ Controls ( $n=236$ ) } & \multirow[t]{2}{*}{ OR } & \multirow[t]{2}{*}{$\mathbf{P}$} \\
\hline & $\mathbf{N}$ & $\%$ & $\mathbf{N}$ & $\%$ & & \\
\hline \multicolumn{7}{|c|}{ Farmer } \\
\hline No & 142 & 69.6 & 160 & 67.8 & \multirow{5}{*}{$1.3(0.6-1.9)$} & \multirow{5}{*}{0.688} \\
\hline Yes & 62 & 30.4 & 76 & 32.2 & & \\
\hline \multicolumn{5}{|c|}{ Regular using pesticides } & & \\
\hline No & 42 & 20.6 & 52 & 22.0 & & \\
\hline Yes & 20 & 9.8 & 24 & 10.2 & & \\
\hline
\end{tabular}

showed that the use of mobile phones had no significant effect in the pathogenesis of pituitary tumors. However, our research shows a very significant impact. Some Chinese scholars' research also showed that mobile phone use had a significant impact on the incidence of brain tumors. We found that few interviewees use an earphone. This may lead to the pathogenesis of pituitary tumors. No significant association was observed with gender, age, education, marriage, speed of eating, fat intake, other taste (salt, sour sweet), medical and reproductive history, female sex hormones, cigarette smoking, tea consumption, wine consumption, menses, use of oral contraceptive, and whether the interviewee was a farmer. $(\mathrm{P}=0.15757,0.94016,0.88658,0.96099,0.37287,0.32429$, $0.24349,0.95711,0.69128,0.06556,0.51930,0.26127$, $0.66306,0.988350 .688390 .5673,0.8953$ respectively). There was no significant associations of pituitary tumor risk with cigarette smoking, tea and wine consumption or past diagnosis of other neoplasms. We have not detected any previous study on the relationship of multiple neoplasms with pituitary tumors.

The potential role of oral contraceptives on the development of pituitary tumor is interesting because estrogen stimulates growth of lactotroph pituitary cells which produce prolactin (15). The studies showed that the animals treated with estrogens have increased numbers of pituitary tumors (2, 4, $8,15,19)$. Therefore, use of oral contraceptive could increase the potential risk for pituitary tumors $(15,24)$. We observed no significant associations of pituitary tumor risk with the use of oral contraceptives. This may be because the age range of our interviewees was wide. Most of them did not use oral contraceptives.

Among control cases, participating subjects were mostly male, old, and more affluent than non-participating subjects. However, this was also observed for cases, which could have compensated for the effect of selective participation of control cases. All analyses were adjusted for age and Townsend deprivation score. Spicy foods can cause choking, increased pressure on the abdomen and chest, and then elevated intracranial pressure. The sauce additives can lead to the occurrence of cancer. Tradition Chinese Medicine also believes that spicy food can lead to occurrence of brain tumors. Different characteristics can cause emotional transformation, thereby affecting blood pressure and intracranial pressure. It is said that pregnant women taking vitamins will be beneficial to reduce the incidence of brain tumors, but the conclusion of this article is just the opposite. There is no other reference evidence to support this conclusion, but this conclusion may be valid. 
There are some limitations for this study. Methodological problems associated with studying risk factors for pituitary tumors may have a long latency time and the different types of pituitary tumor might have different etiologies $(1,15)$.

\section{CONCLUSION}

An increased risk of pituitary tumor is present in relation with spicy taste, mobile phone using, duration of use, characteristics, taking vitamins and possibly a reduced risk with whether the interviewee was a worker. The causes of these associations need further investigation with larger populations.

\section{ACKNOWLEDGEMENT}

We are grateful all participants for their valuable contributions to this study.

\section{REFERENCES}

1. Anonymous: Pituitary adenomas and oral contraceptives: A multicenter case-control study. Fertil Steril 39: 753-760, 1983

2. Asa SL, Ezzat S: The pathogenesis of pituitary tumours. Nat Rev Cancer 2:836-849, 2002

3. Beckers A, Daly AF: The clinical, pathological, and genetic features of familial isolated pituitary adenomas. Eur $\mathrm{J}$ Endocrinol 157: 371-382, 2007

4. Christin-Maitre S, Delemer B, Touraine P, Young J: Prolactinoma and estrogens: Pregnancy, contraception and hormonal replacement therapy. Ann Endocrinol 68:106-112, 2007

5. Coogan PF, Baron JA, Lambe M: Parity and pituitary adenoma risk. J Natl Cancer Inst 87:1410-1411, 1995

6. Coulam CB, Annegers JF, Abboud CF, Laws ER Jr, Kurland LT: Pituitary adenoma and oral contraceptives: A case-control study. Fertil Steril 31: 25-28, 1979

7. DeLellis R, LLoyd R, Heitz P, Eng C: Pathology and genetics of tumors of endocrine origin. IARC WHO Classification of Tumours. Lyon: World Health Organization, 2004:1-320

8. Gold EB: Epidemiology of pituitary adenomas. Epidemiol Rev 3: 163-183, 1981

9. Hemminki K, Chen B: Are twins at risk of cancer: Results from the Swedish family-cancer database. Twin Res Hum Genet 8: 509-514, 2005

10. Hemminki K, Forsti A, Ji J: Incidence and familial risks in pituitary adenoma and associated tumors. Endocr Relat Cancer 14:103109, 2007
11. Hemminki K, Jiang Y: Second primary neoplasms after 19281 endocrine gland tumours: Aetiological links? Eur J Cancer 37: 1886-1894, 2001

12. Jones JR, Kemmann E, Norwood PK: Oral contraceptive exposure of amenorrheic women with and without prolactinomas. Int $J$ Gynaecol Obstet 19: 381-387, 1981

13. Kameya T, Tsukada T, Yamaguchi K: Recent advances in MEN1 gene study for pituitary tumor pathogenesis. Front Horm Res 32 : 265-291, 2004

14. Maheux R, Jenicek $M$, Cleroux R: Oral contraceptives and prolactinomas: A case-control study. Am J Obstet Gynecol 143: 134-138, 1982

15. Schoemaker MJ, Swerdlow AJ: Risk of pituitary tumors in cellular phone users: A case-control study. Epidemiology 20(3):348-354, 2009

16. Shy KK, McTiernan AM, Daling JR, Weiss NS: Oral contraceptive use and the occurrence of pituitary prolactinoma. JAMA 249: 2204-2207, 1983

17. Stata Corp. Stata Statistical Software: Release 9.0. College Station, Texas: Stata Corporation 2006

18. Statistics Netherlands. Blaise: Voorburg/Heerlen: Statistics Netherlands 2003

19. Stefaneanu L. Experimental models of pituitary tumorigenesis. In Thapar K (ed). Diagnosis and Management of Pituitary Tumours. Totowa (NJ): Humana Press, 2001:81-90

20. Takebayashi T, Varsier N, Kikuchi Y, Wake K, Taki M, Watanabe $\mathrm{S}$, Akiba S, Yamaguchi N: Mobile phone use, exposure to radiofrequency electromagnetic field, and brain tumour: A casecontrol study. Br J Cancer 98(3): 652-659, 2008

21. Teperman L, Futterweit W, Zappula R, Malis LI: Oral contraceptive history as a risk indicator in patients with pituitary tumors with hyperprolactinemia: A case comparison study of twenty patients. Neurosurgery 7: 571-573,1980

22. Townsend $P$, Phillimore $P$, Beattie $A$ : Health and Deprivation: Inequality and the North. New York: Croom Helm, 1988

23. Vance ML: Treatment of patients with a pituitary adenoma: One clinician's experience. Neurosurg Focus 16: E1, 2004

24. Vierimaa O, Georgitsi M, Lehtonen R: Pituitary adenoma predisposition caused by germline mutations in the AIP gene. Science 312: 1228-1230, 2006

25. WHO: International Statistical Classification of diseases and related health problems, 10th revision. Geneva: World Health Organization 1992

26. Wingrave SJ, Kay CR, Vessey MP: Oral contraceptives and pituitary adenomas. Br Med J 280:685-686, 1980 